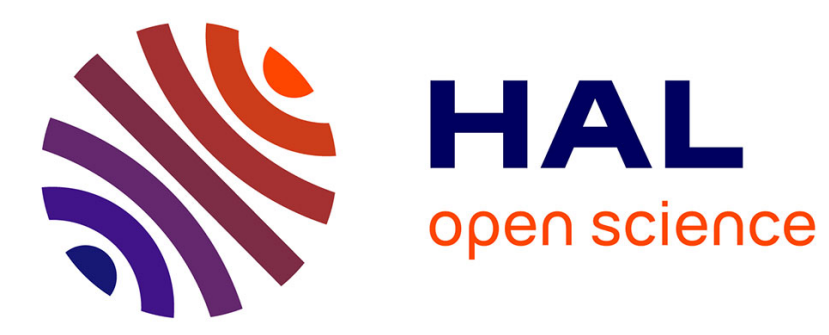

\title{
On diminutives and plurals in Moroccan Arabic
}

Mohamed Lahrouchi, Rachid Ridouane

\section{To cite this version:}

Mohamed Lahrouchi, Rachid Ridouane. On diminutives and plurals in Moroccan Arabic. Morphology, 2016, 26 (3-4), pp.456-475. 10.1007/s11525-016-9290-7 . hal-01324192

HAL Id: hal-01324192

https://hal-univ-paris8.archives-ouvertes.fr/hal-01324192

Submitted on 15 Jun 2021

HAL is a multi-disciplinary open access archive for the deposit and dissemination of scientific research documents, whether they are published or not. The documents may come from teaching and research institutions in France or abroad, or from public or private research centers.
L'archive ouverte pluridisciplinaire HAL, est destinée au dépôt et à la diffusion de documents scientifiques de niveau recherche, publiés ou non, émanant des établissements d'enseignement et de recherche français ou étrangers, des laboratoires publics ou privés. 


\title{
On diminutives and plurals in Moroccan Arabic
}

\author{
Mohamed Lahrouchi \& Rachid Ridouane
}

Plural nouns in Moroccan Arabic (henceforth MA), like in many other Afroasiatic languages, can be formed through internal or external morphological operations; the nouns are thus distinguished as either 'broken' (internal) or 'sound' (external). In many cases, however, a single noun displays both plural forms (for instance, $t^{\varsigma} \partial s^{\varsigma}$ wera 'photo' has plurals $t^{\uparrow} S^{\varsigma} a w \partial r$ and $t^{\varsigma} \partial s^{\varsigma}$ werat; gamila 'bowl' leads to gwamal and gamilat). Interestingly, the diminutive systematically resorts to -at suffixation in the plural: $t^{\varsigma} S^{\varsigma}$ ewera 'small photo' and gwimila 'small bowl' form their plurals as $t^{\uparrow} S^{\varsigma}$ ewerat and gwimilat respectively.

The fact that all diminutive forms select for external plurals suggests some kind of constraint that prohibits infixing the diminutive and plural markers at the same time. From a phonological point of view, there is no reason why such infixes cannot co-occur in the same form. Therefore, the resulting alternation in the plural formation, which can be viewed as a type of allomorphy, will be argued to follow from a templatic constraint that forces diminutives to systematically use suffixation when pluralized. It will be shown that the diminutive and the plural infixes compete for the same templatic position, resulting in forms where only the diminutive marker surfaces.

The broken and sound plurals that nouns like $t^{\varsigma} \partial s^{\varsigma}$ wera and gamila display will be shown to involve a crucial semantic contrast: $t^{\varsigma} \partial s^{\varsigma}$ werat and gamilat, indicate a definite number, usually occurring with numerals, whereas $t^{\uparrow} s^{\varsigma} a w a r$ and gwamal have a collective reading. This contrast along with the morphological differences will be accounted for by positing that broken and sound plurals reside in different syntactic locations. The latter will be argued to be associated with the standard Num projection, whereas the first are associated lower in the structure with the $n$ projection. External evidence in favour of this analysis is drawn from the phenomenon of emphasis spread. It will be shown that the emphatic coronals spread their feature to the neighbouring segments within the $n P$ domain. That is to say, broken plurals containing an emphatic consonant will be entirely emphaticized, while sound plurals will be affected only partially. The same reasoning holds for diminutives, whose singular forms are fully emphaticized. 
This paper is structured as follows. Section 1 discusses the semantic and morphological differences between broken and sound plurals in MA. A morpho-syntactic analysis is proposed, which aims to capture these differences. Section 2 turns to diminutives. A templatic approach is developed in order to explain why diminutives systematically resort to -at suffixation in the plural. Section 3 provides phonetic and phonological evidence for the analysis proposed in section 1: emphasis is argued to spread within the domain of nP. Section 4 concludes the paper.

\section{Plurals in Moroccan Arabic nouns}

Nouns in MA are marked for singular and plural, but lack the dual of Classical Arabic. Plurals are generally formed by means of infixation (e.g. wald / wlad 'boys'), vowel alternation (e.g. kta:b / ktu:b 'books') or suffixation (e.g. mußallim / mu?allim-in 'teacher.MS'; hrajfi / hrajfij$a$ 'craftsman'). Note that the suffix $-a$ also occurs in the feminine forms (e.g. hrajfij- $a$ 'craftswoman'; xəjjat ${ }^{\varsigma}$ 'tailor.MS' / xəjjat ${ }^{\varsigma}-a$ 'tailor.FM'). Further details and analysis are provided in Heath (1987).

Nouns displaying more than one plural form are not specific to Arabic. Many other languages in the Afroasiatic family, such as Somali, Hausa and Amharic, have been reported to show similar forms (see Newman 2000: 463 on Hausa, Puglielli and Siyaad 1984 and Lecarme 2002 on Somali, and Kramer 2012: 227 on Amharic). In most cases, these forms involve socalled double pluralization, whereby one plural form derives from another plural. In Amharic, for instance, singular mämhir 'teacher' leads to plurals mämhiran and mämhiranotfts. Likewise, Somali naág ‘woman' has plurals naagó ‘women’ and naagayáal $(\longleftarrow / n a a g+o+y a a l /)$ 'groups of women', ${ }^{1}$ and Hausa dó:kì: 'horse' has plurals dáwá:kí: and dàwà:kái. In MA, however, there are very few double plurals, such as mwasat 'knives' (plural of plural mwas) and qwasat 'arches' (plural of plural qwas). In this section, we focus on the analysis of nouns that have two independent plural forms in MA, as illustrated in (1).

\footnotetext{
${ }^{1}$ One might argue that affix ordering in double plurals runs counter the hypothesis put forth here since the suffix -ó, which derives regular plurals, is added before -yáal. Yet these formations differ from the ones at hand in MA since they involve double pluralization. As far as the parallel holds, we can assume that Somali plurals using -ó are generated under nP (see Lecarme 2002: 193), similarly to what we propose for MA internal plurals.
} 


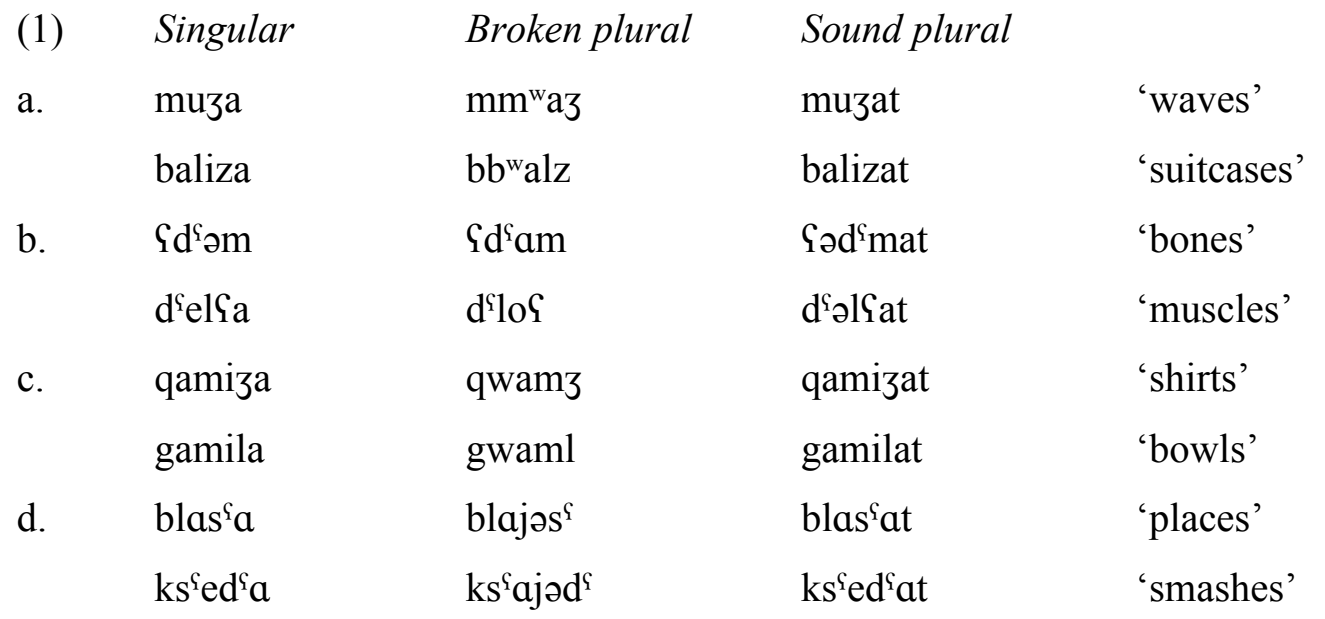

These examples involve native words and loans alike. They are classified depending on the morphological operations used in the broken plurals: gemination in (1a), vowel insertion in (1b), -wa- infixation in (1c) and -jo- infixation in (1d); sound plurals invariably resort to -at suffixation. Interestingly, broken plurals are often semantically associated with collective readings, while sound plurals are count nouns referring to a definite number, especially when used with a numeral. ${ }^{2}$ One could argue that this semantic distinction is subject to variation - that certain broken plurals can indicate definite numbers. However, as far as we know, sound plurals are hardly ever associated with collective readings. None of the sound plurals listed above indicates an indefinite number, especially not when used with a numeral. Furthermore, it is worth noting that -at suffixation entails feminine gender, regardless of the gender of the singular. This is manifested through agreement relations as in the following examples, where İd $^{\prime} m a t$ 'bones' (2a) is feminine while singular $\mathcal{G} d^{\varsigma} \partial m$ 'bone' (2b) and internal plural $\mathcal{C} d^{\varsigma} a m(2 \mathrm{c})$ are masculine. ${ }^{3}$

\footnotetext{
${ }^{2}$ One of the anonymous reviewers rightly pointed out that certain numerals in MA select broken plurals. For instance, tlata 'three' can be used with broken plurals, as opposed to zuz 'two' which combines with sound plurals. In fact, these numerals behave differently since they involve distinct syntactic structures.
a. tlata $d \quad t t^{\varsigma} s^{\varsigma} a w a r$ three of the-photos
'three photos'
b. $3 u 3$ t $t^{\varsigma} s^{\varsigma}$ werat two photos
'two photos'

As the careful reader will have noticed, a genitive preposition $d$ intervenes between tlata and the following broken plural but not between $z u z$ and its sound plural. The complement of the genitive preposition when plural can be only internal, with a collective reading which requires a numeral in order to be quantified. For the sake of completeness, we should also note that the absence of the genitive preposition in (b) leads to a construct state formation where the sound plural $t^{\varsigma} \partial s^{\varsigma}$ werat occurs without a determiner, as opposed to the broken plural $t t^{\varsigma} S^{\varsigma} a w \partial r$ whose geminate results from the concatenation of the determiner $l$ - and the stem-initial consonant.

${ }^{3}$ One could argue that $\varsigma \partial d^{\varsigma} m a t$ alternates with feminine singular $\zeta \partial d^{\varsigma} m a$ whereas masculine $\zeta d^{\varsigma} \partial m$ has plural $\varsigma d^{\varsigma} a m$, therefore suggesting that masculine forms select only internal plurals while feminine forms opt for external plurals.
} 
(2)

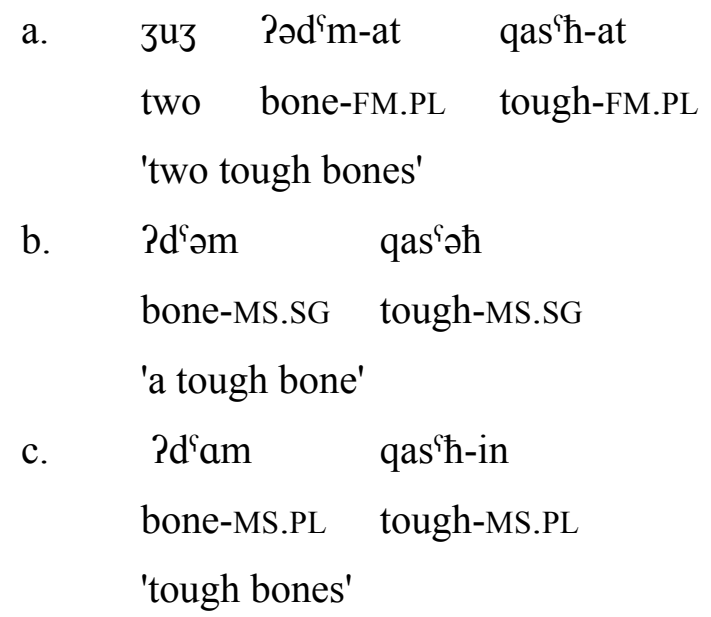

The facts just discussed suggest that MA broken and sound plurals reside in distinct syntactic positions. Following Lahrouchi \& Lampitelli (2014), we assume that sound plurals in MA are associated with the standard number projection (numP), whereas broken plurals are associated lower in the structure with the noun projection $(n P){ }^{4}$ The forms represented in (3) illustrate the analysis.

b. Sad'mat 'muscles'
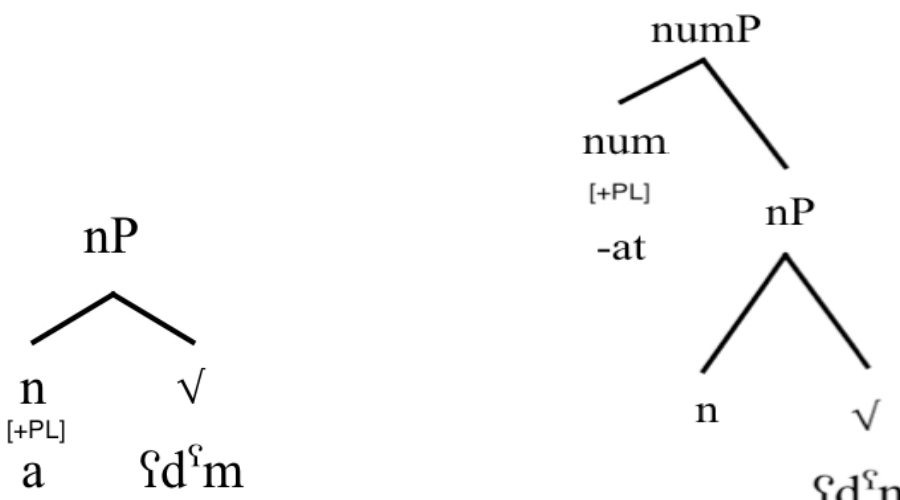

$\mathrm{Sd}^{\mathrm{i}} \mathrm{m}$

According to Marantz (2001 and 2007; see also Embick \& Marantz 2008, and Embick \& Noyer 2007: 296), roots are acategorial. As such, they need to combine with functional heads

This correspondence is, however, far from being systematic as we find plenty of feminine nouns which resort to internal plural formation. Singular forms ending with -a in (4) are actually feminine but they all have internal plurals as well as external ones. The behaviour of feminine nouns clearly shows that gender specification is irrelevant in the choice of the type of plural formation.

${ }^{4}$ The reader is referred to Lowenstamm (2008), Acquaviva (2008) and Kramer (2012) for further details about number and plurality. 
such as $v, n$ or $a$, the first category-determining heads in the syntactic structure. In line with this proposal, we assume that $S d^{\varsigma} a m$ (3a) is formed by combining the head $n$, which has a plural feature, with an acategorial root, while Sad'mat (3b) obtains its plural feature higher in the structure, from numP. These structures allow one to capture the morphological and semantic differences that broken and sound plurals display. Moreover, the lower location of broken plurals, close to the root, accounts for their morpho-phonological irregularity, while the higher location of sound plurals represents their regularity and their high productivity in most noun classes. ${ }^{5}$ It is worth noting that loanwords (e.g. taksi 'cab' / taksiyat 'cabs', t'obis 'bus' / t'obisat 'buses') and diminutives, to which we will turn in the following section, all resort to -at suffixation. The same holds for mass nouns, especially when used with numerals (e.g. zitun 'olive' / zuz zitunat 'two olives', $x u b z$ 'bread' / zuz xubzat 'two loaves of bread'). ${ }^{6}$ This is somewhat consistent with Borer's proposal (2005: 96) according to which nominalized roots are basically interpreted as mass before additional functional structure is added to derive a count reading. The parallel is simplified here for expository reasons. Strictly speaking, Borer suggests that roots are acategorial and unspecified for mass or count, but assigning a count reading to a root requires additional functional projections compared to a mass reading. In the same vein, the collective reading associated with broken plurals in MA can be assumed to be derived lower in the structure than the count reading assigned to sound plurals.

\footnotetext{
${ }^{5}$ See Marantz $(2001,2007,2013)$ and Arad $(2003,2005)$ who show that words derived by combining a root and a category-defining head are more prone to morpho-phonological and semantic irregularities, as opposed to words derived from other words.

6 In MA, mass nouns are singular just as English water and sugar. This is expressed through their agreement:

e.g. l-hut yali the-fish expensive.SG 'Fish is expensive'

Their plural, systematically formed by means of - at suffixation, makes them count. This further argues for the fact that sound plurals indicate a definite number.
} 


\section{Diminutives}

\subsection{An overview of diminutive formations}

Cross-linguistically, diminutives denote smallness or endearment. They are generally assumed to be derived from other words, usually nouns, by adding a suffix, as in English sweetie, doggy and booklet or in Italian finestrella 'little window' and casetta 'little house'. In French, feminine nouns tend to use the suffix -ette (e.g. maisonette 'little house', fillette 'little girl'). Masculine nouns may also use this suffix switching their gender into feminine (e.g. camion 'truck' / camionette 'little truck', char 'tank' / charrette 'cart'), while others use -on [õ] or -ot / eau [o] (e.g. oisillon 'small bird', chaton 'kitten', chariot 'trolley', baleineau 'calf, young whale'). In certain cases, however, these suffixes are hardly associated with a diminutive meaning. For instance, it is not clear how small is ballon 'ball' compared to balle 'ball' nor is it obvious that salon 'living room' is a diminutive of salle 'hall' (the reader is referred to Lowenstamm 2008 on this issue).

In many branches of the Afroasiatic family, including Berber, Cushitic and Chadic, feminine markers are used to derive diminutives. For example, in Tashlhiyt Berber, $t$ - prefixed and suffixed to masculine nouns indicates not only feminine but also a small size: e.g. afus 'hand' / t-afuss-t 'small hand', ayalim 'reed' / t-ayalim-t 'small reed, fishing rod', compared to the masculine gender which can be used as an augmentative (e.g. $t$-akur-t 'ball' / akur 'big ball', $t$ agrtil-t 'mat' / agrtil 'large mat'). Similarly, Gidar (a Chadic language) uses the feminine suffix $k\left(\partial^{\prime}\right)$ to mark diminutive as in gəmdá-kə 'small chicken' and $k \partial^{\prime} r-k$ 'small dog' (cf. Frajzyngier 2003: 86, 2008). Semitic languages such as Arabic and Hebrew opt for internal morphology to mark the diminutive, though in the latter case the process is predominantly suffixal (cf. De Belder et al. 2015).

In Classical Arabic (henceforth CA), diminutives show a regular prosodic pattern, typically of the form $\mathrm{CuCajC}$, which varies slightly depending on the number and length of base segments: e.g. kulajb 'small dog' / kalb 'dog', nufajs 'small soul' / nafs 'soul', kutajjib 'little book' / kita:b 'book', sulajt ${ }^{\varsigma} i: n$ 'little Sultan' / sult ${ }^{\varsigma} a: n$ (cf. McCarthy \& Prince 1990: 222). MA uses almost the same pattern, except for the absence of the vowels $u$ and $a$ in the surface form. Following Lowenstamm (1991), we will argue later in this section that this phenomenon results from the absence of phonologically short peripheral vowels in Moroccan Arabic. 


\subsection{Diminutives in Moroccan Arabic}

The data in (4) illustrate the various forms of diminutives in MA. The reader is referred to Elmdari (1999), Boudlal (2001) and Arbaoui (2015) for further examples.

\begin{tabular}{|c|c|c|c|c|c|}
\hline (4) & Singular & Plural & Diminutive & Plural of diminutive & \\
\hline \multirow[t]{3}{*}{ a. } & bəl $\gamma \mathrm{a}$ & blayi & bliya & blijat & 'slipper' \\
\hline & dəmৎa & dmuS & dmiSa & dmiSat & 'tear' \\
\hline & kura & kwari & kwira & kwirat & 'ball' \\
\hline \multirow[t]{3}{*}{ b. } & bənt & bnat & bnita & bnitat & 'girl' \\
\hline & $d^{\complement} a r$ & d'jor & dwira & dwirat & 'house' \\
\hline & Sin & Sjun & Swina & Swinat & 'eye' \\
\hline \multirow[t]{3}{*}{ c. } & wəld & wlad & wlijjəd & wlijdat & 'boy’ \\
\hline & 3məl & 3mal & 3mijjəl & 3mijlat & 'camel' \\
\hline & $s^{\varsigma} b ə c$ & $\mathrm{~s}^{\complement} \mathrm{baC}$ & $\mathrm{s}^{\mathrm{f}}$ bejjə؟ & $s^{\complement}$ bejৎat & 'finger' \\
\hline \multirow[t]{3}{*}{ d. } & ktab & ktub & $\mathrm{k}^{\mathrm{w}}$ tijjəb & $\mathrm{k}^{\mathrm{w}}$ tijbat & 'book' \\
\hline & kəlb & klab & $\mathrm{k}^{\mathrm{w}}$ lijjəb & $\mathrm{k}^{\mathrm{w}}$ lijbat & 'dog' \\
\hline & qəlb & qlub & $\mathrm{q}^{\mathrm{w}}$ lijjəb & $\mathrm{q}^{\mathrm{w}}$ lijbat & 'heart' \\
\hline \multirow[t]{3}{*}{ e. } & bit & bjut & $b b^{\mathrm{w}} \mathrm{ijj} \partial \mathrm{t}$ & $b b^{\mathrm{w}}$ ijtat & 'room’ \\
\hline & mus & mwas & $\mathrm{mm}^{\mathrm{w}} \mathrm{ijj} ə \mathrm{~s}$ & $\mathrm{~mm}^{\mathrm{w}}$ ijsat & 'knife' \\
\hline & buq & bwaq & $b b^{\mathrm{w}} \mathrm{ijj} \partial \mathrm{q}$ & $\mathrm{bb}^{\mathrm{w}}$ ijqat & 'loud speaker' \\
\hline \multirow[t]{3}{*}{ f. } & sərwal & srawəl & sriwil & sriwilat & 'pants' \\
\hline & $t^{\complement} \partial b s^{\complement} e l$ & $t^{\mathrm{f}} \mathrm{bas} \mathrm{s}^{\mathrm{S}} \mathrm{l}$ & $t^{\mathrm{f}} \mathrm{bes} \mathrm{s}^{\mathrm{C}} \mathrm{l}$ & $\mathrm{t}^{\mathrm{f}}$ bes ${ }^{\mathrm{f}}$ elat & 'plate' \\
\hline & dəbliz & dbaləz & dbiliz & dbilizat & 'bracelet' \\
\hline
\end{tabular}

These data are sorted into six classes depending on the way the diminutive is formed. Plurals are given for both diminutive and non-diminutive forms in order to show how the diminutive impacts the plural. In terms of surface syllabic structure, all diminutive singulars consist of two syllables regardless of the number of syllables in the base form. ${ }^{7}$ A more interesting generalisation is that the infix $-i$ - is inserted between the last two consonants of all diminutives: basic feminine forms in $(4 a, b)$ use this infix along with the suffix $-a$, which marks

\footnotetext{
${ }^{7}$ Some authors, arguing that MA does not allow complex onsets, view these forms as having three syllables, (Boudlal 2001, Kiparsky 2002, Dell and Elmedlaoui 2002). A form like bnita is thus syllabified [b.ni.ta], where /b/ stands for a syllable of its own (see also Shaw et al. 2010).
} 
feminine, while the remaining masculine forms involve -ijj-infixation $(4 \mathrm{c}-\mathrm{e}),{ }^{8}$ with the exception of quadriconsonantals (4f) which display $-i$ - twice; between $C_{2}$ and $C_{3}$, and between $C_{3}$ and $C_{4}$. The data also show forms with a velar or uvular $\mathrm{C}_{1}$ that undergoes labio-velarization in the diminutive. This feature probably originates from the loss in MA of the vowel $u$ found in CA diminutives. This will be used later as evidence in favour of the assumption that CA short vowels are dropped in MA while long vowels surface as short.

The crucial observation for the purpose of our analysis is that all diminutives in MA resort to -at suffixation in the plural while their base forms may select for broken plurals. The question is why diminutives like bliza and wlijjad do not form their plural by means of infixation, combining both markers in the same form.

In what follows, we will attempt to provide an answer to this question by arguing that the plural of diminutives can only be external, as the templatic site located between the last two radicals hosts the diminutive infix.

\subsection{A templatic approach}

Before turning to the role of the template in deriving MA diminutives, let us briefly review some alternative approaches to the regularity of these forms. This regularity can be accounted for in terms of prosodic circumscription à la McCarthy \& Prince (1990), be it representational or constraint-based. As in the case of CA plurals and diminutives, one can argue that in MA each diminutive form has to display a LL or LH iamb. This is actually consistent with the data in (4), as long as we consider the intervocalic geminates to be weightless. For instance, a form like wlijjad 'little boy' could be syllabified into LH, where the ambisyllabic geminate does not contribute to weight.

The diminutive marker can be analysed as a suffix attached to a circumscribed part of the base which corresponds to a minimal syllable of the form CV or CəC (El Ghadi 1990, Bennis 1992). For example, wald 'boy' can be analysed as wəl $<\mathrm{d}>$ where the bracketed consonant is not part of the circumscribed target for affixation. The diminutive marker is suffixed to the circumscribed syllable, leading to walid, whose schwa is not realized since followed by a consonant-vowel sequence (see 2.3.1 for details about ə/ø alternations in MA). Then a default syllable $j j$ is added in order to satisfy a LH iambic foot, resulting in the form wlijjad, in which

${ }^{8}$ It should be noted here that j-gemination is subject to variation. According to Elmdari (1999: 82), forms like in (4c-e) display a non-geminated glide in the MA variety of Marrakech. 
geminated $j j$ does not contribute to weight (see El Ghali 1990 and Boudlal 2001: 252 for further details about this analysis). ${ }^{9}$

Any phonological theory that wants to account for the diminutive data should involve a clear definition of the possible kinds of interaction between phonology and morphology, and it should capture the co-occurrence restrictions that the diminutive and the broken plural markers display. That is, it should explain why the diminutive marker is always infixed exactly where the broken plural is expected, forcing all diminutives to use the suffix $-a t$ in the plural. In the remainder of this section, we will bring out more explicitly the templatic mechanism responsible for this phenomenon. To do so, we need to outline the main assumptions about the representation of the skeletal tier and the syllable structure in the framework adopted here.

\subsubsection{CVCV model}

The CVCV model (Lowenstamm 1996), which falls within the framework of Government Phonology as outlined in Kaye, Lowenstamm \& Vergnaud (1990), holds that syllable structure universally reduces to a strict alternation of non-branching onsets and non-branching nuclei, viz. $\mathrm{C}$ and $\mathrm{V}$ positions. These positions interact laterally to derive different surface syllable types. Only consonantal segments are linked to $\mathrm{C}$ positions and only vocalic segments appear in $\mathrm{V}$ positions. The differences in the surface syllabic structures lie in the way segments are associated to the skeletal tier. That is, in a closed syllable, the consonant in the coda position is followed by an empty $\mathrm{V}$ position, a branching onset and a geminate contain an empty $\mathrm{V}$ between its consonants, while a long vowel contains an empty C. This is illustrated below in (5).

\footnotetext{
${ }^{9}$ Such prosodic analyses are tenable only at the expense of stipulating that neither ambisyllabic geminates nor wordfinal consonants contribute to weight. In addition, as Boudlal (2001: 253) noticed, prosodic circumscription fails to account for forms like zmal 'camel' since the diminutive suffix should be added after the circumscribed syllable mal, leading to *zamli rather than zmijjal. Similar problems arise with biconsonantal bases such as bit 'room', in which neither a CV nor a CəC syllable type is available.
} 
(5)

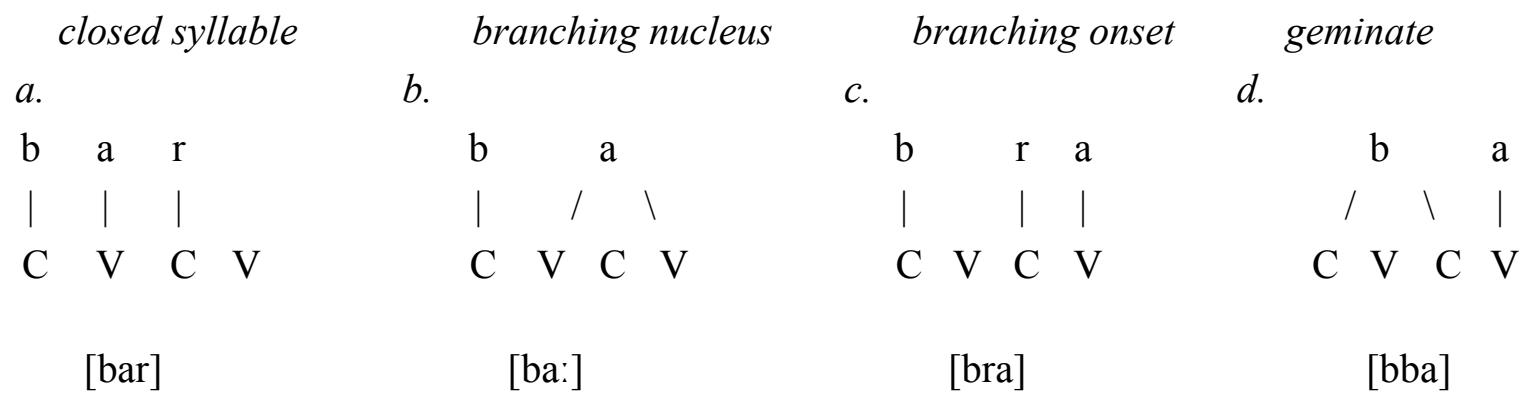

In addition, skeletal positions that have no phonetic realization are licensed to remain empty by virtue of the government relation that they share with the neighbouring segments. Proper Government $(\mathrm{PG})$ is one such relation, allowing a vocalic position to remain empty when followed by a vowel. This proves particularly interesting in explaining the $/$ /ø alternation in Moroccan Arabic. For example, qlab 'he reversed' where the $\mathrm{V}$ position between /q/ and /1/ is properly governed by the following schwa and thus remains empty (6a), in contrast with qalbu 'they reversed' where the same position, non-governed, surfaces as schwa (6b).

(6)

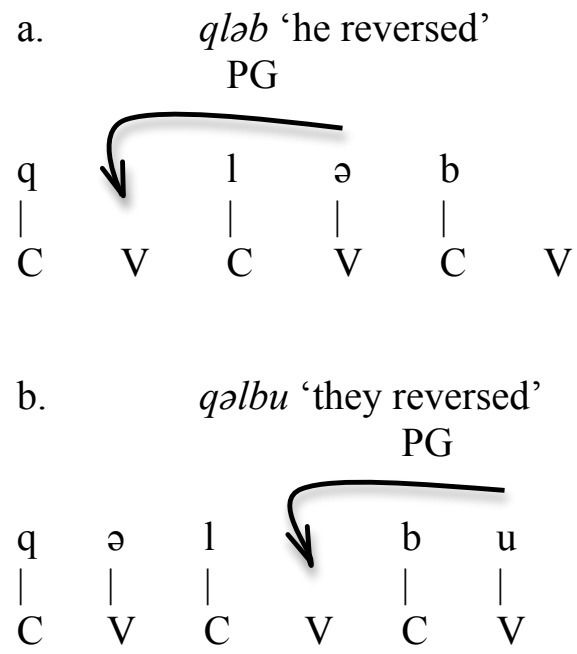

This kind of lateral relation proves necessary in explaining why the schwa following the diminutive infix in the forms in (4c-e) like wlijjad is dropped when the plural suffix -at is added. Within the CVCV approach, the $\mathrm{V}$ position between $j$ and $d$ surfaces as schwa in wlijjad since it is not governed, but remains empty in wlijdat since it is governed by the following $a$. At the same time, we notice that the diminutive infix surfaces with a geminated glide in the singular diminutive forms in $(4 \mathrm{c}-\mathrm{e})$ but not in the corresponding plural forms. In other words, the glide 
geminates when followed by schwa and remains unchanged when followed by a consonant. We will turn back to this point later in section 2.3.3.

\subsubsection{MA peripheral vowels}

Another issue that needs to be addressed before turning back to diminutives relates to the phonological representation of MA vowels. MA has only four vowels, three of which are peripheral /i, a, u/. The fourth vowel is a schwa, whose distribution is phonotactically predictible as shown in the examples represented in (6). In certain cases, $/ \mathrm{i} /$ and $/ \mathrm{u} /$ may surface as midvowels [e] and [o], especially when pharyngealized or adjacent to a guttural consonant (see section 3 for examples and discussion).

Following Lowenstamm's hypothesis (1991) about the vocalic system of Maghribi Arabic and Ethio-Semitic, we assume that the peripheral vowels of MA are associated with 'branching nuclei'. The parameter is stated as follows:

(7) In MA, peripheral vowels must be associated with two V positions.

According to this parameter, the representation of the three peripheral vowels of MA follows under (8).

$\begin{array}{lccr}\text { skeletal level } & \text { CVCV } & \text { CVCV } & \text { CVCV } \\ \text { segmental level } & \mathrm{I} & \mathrm{U} & \mathrm{A} \\ \text { phonetic realization } & {[\mathrm{i}]} & {[\mathrm{u}]} & {[\mathrm{a}]}\end{array}$

Note that the parameter in (7) is a condition on the association of vocalic elements to the skeletal level. It does not affect the segmental level. Thus, the three peripheral vowels always surface as short vowels, viz. [i], [a] and [u].

The correspondences between MA and CA endorse the above proposal. Indeed, in a number of items shared by these languages there is a regular change whereby the long vowels of CA correspond to phonetically short vowels in MA. Short vowels in CA disappear in MA, leading to a situation where any position that is not properly governed surfaces as schwa. In contrast, singleton and geminate consonants in CA are preserved as such in MA. The examples in (9) illustrate these correspondences. 


\section{Classical Arabic $\quad$ Moroccan Arabic}

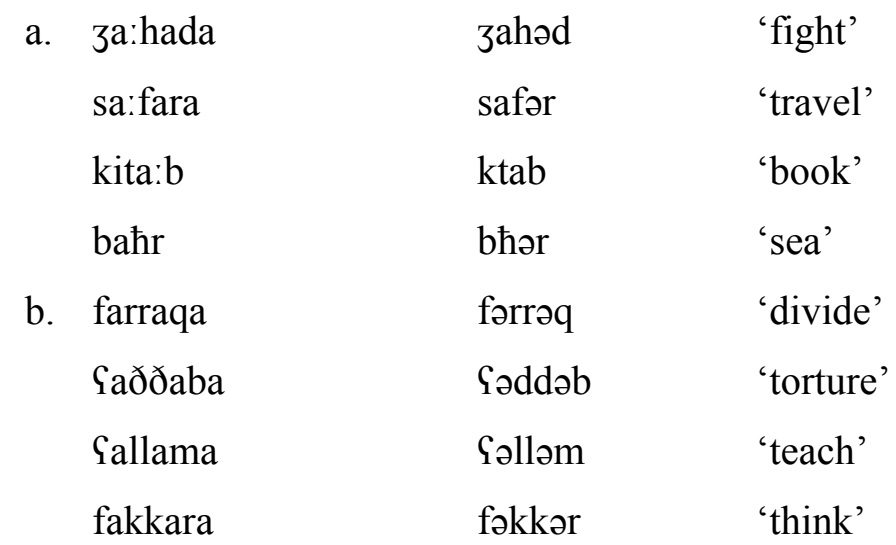

The parameter in (7) characterizes these correspondences by distinguishing the vowels that occupy two vocalic positions from those that have access to only one position. The first surface as short in MA, while the latter remain silent.

\subsubsection{A templatic effect}

Templatic morphology, which goes back to McCarthy's seminal work $(1979,1981)$ on verb conjugation in Classical Arabic, offers an interesting descriptive potential, some aspects of which meet with the facts discussed in section 2.2. McCarthy's work has taken advantage of autosegmental representations. The idea is that linear objects such as kattab 'he made write' decompose into distinct morphemes, one of which is the template whose shape allows deriving medial consonant gemination, as opposed to vowel-lengthening in ka:tab 'he corresponded'. Templates are thus about the management of syntagmatic space in languages where quantity distinctions (short vs. long segments) count more than quality distinctions. They are viewed as fully-fledged morphemes, which may consist of any string of $\mathrm{C}$ and $\mathrm{V}$ positions ordered in a fixed way so that they convey specific grammatical information.

In order to reduce the number of templates proposed by McCarthy (1981: 396), Guerssel \& Lowenstamm (1990) and Lowenstamm (2003) suggest that the verbal forms of Classical Arabic are derived by means of a single template, composed of four CV units, one of which is an empty site that may host various operations, including consonant gemination and vowellengthening. ${ }^{10}$ This is illustrated in (10).

\footnotetext{
${ }^{10}$ The idea of reducing the number of templates in the verbal conjugation of Classical Arabic is not new. McCarthy (1979: 135) has already suggested expressing the regularities that the verbal forms and their canonical patterns show by means of two templates: $\operatorname{CV}((\mathrm{CV})[+$ seg] $) \mathrm{CVC}$ and $\mathrm{CCV}([+\mathrm{seg}]) \mathrm{CVC}$. The first template abbreviates the
} 
(10) a. qattal

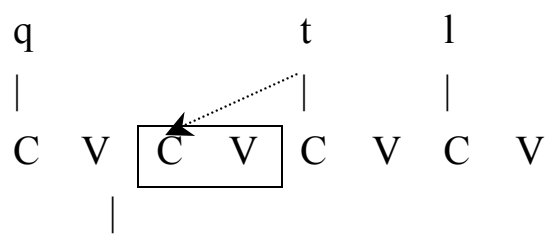

a b. qa:tal

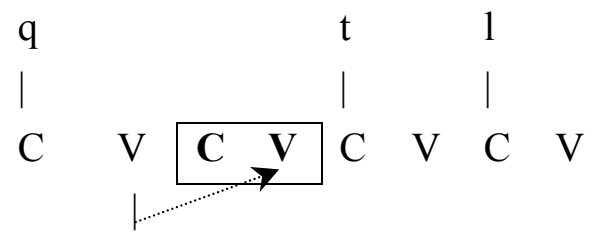

a

The boxed CV is viewed as a morphological head whose only specification is being derivational. The identification of one of its positions by some affix or root material derives one verbal form. For example, given the triconsonantal root $q t l$ 'kill', if the derivational site is filled by means of C-spreading, the resulting verb will be qattal 'he massacred (intensive)' (10a), whereas its identification by means of V-spreading leads to the form qa:tal 'he fought (reciprocal)' (10b). ${ }^{11}$ If none of its positions is identified, the output is qatal 'he killed', which stands for the basic form of the verb, also called Form I in standard analyses. Although semantically viable, the intensive reciprocal *qa:ttala is ruled out because it involves the identification of both $\mathrm{C}$ and $\mathrm{V}$ positions at the same time.

In line with the above proposal, we can posit that diminutives in MA are formed by means of a specific template, whose antepenultimate CV unit acts as a derivational head. ${ }^{12}$ Singular diminutives in (4) can be derived by means of a fixed shape template, whose antepenultimate CV hosts the diminutive marker. This marker is argued to be a high front unrounded vowel /i/, which connects to two V positions, as shown in (11).

patterns CVCVC, CVCCVC, CVVCVC, CVCVCCVC and CVCVVCVC. The second abbreviates the patterns CCVCVC, CCVCCVC and CCVVCVC.

${ }^{11}$ It is worth noting that no single semantic feature is associated with the derivational CV: verbs using medialconsonant gemination may be intensive, causative or just transitive, while those with a long vowel are not always reciprocal (e.g. sa:fara 'he travelled', d'a: 'afa 'he doubled').

12 In this respect, it is interesting to note that nouns differ from verbs in that the latter use internal morphology between the first two root consonants, while nouns generally resort to infixation between the last two consonants (e.g. kita:b 'book', rima:l 'sands') 
(11) $a$.

DIM FM SG: bli $a$

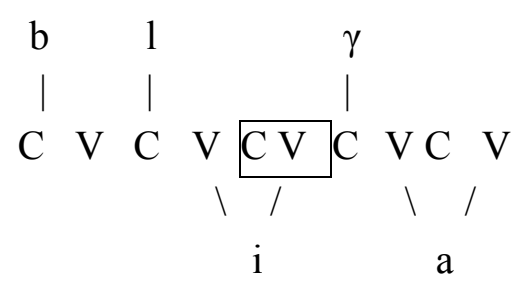

$b$.

DIM MS SG: wlijjad

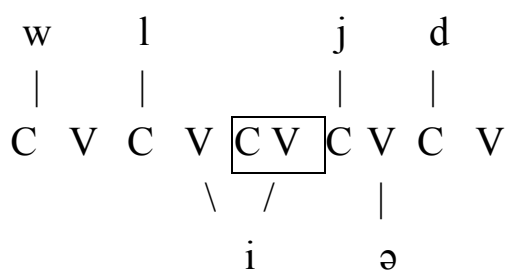

As can be seen from these representations, the template consists of five CV units, three of which accommodate the root consonants, while the others host long vowels and epenthetic elements. The derivational boxed $\mathrm{CV}$ allows the diminutive marker/i/ to connect to two $\mathrm{V}$ positions. However, in (11b), the diminutive marker ends up in contact with the following syllable, whose nucleus surfaces as schwa since properly ungoverned. The resulting hiatus is then resolved by $j$ epenthesis, leading to the form wlijjad. The geminated [jj] could be a mere phonetic by-product of the co-articulation of a high vowel followed by a glide $\mathrm{j}$ or the result of an off-gliding $\left[\mathrm{i}^{\mathrm{j}}\right]$ that anticipates the realization of the next sound, which is a glide itself. ${ }^{13}$

Interestingly, the addition of the plural suffix - at to a form like wlijjad, leads not only to the vocalic position preceding the last root consonant remaining empty (since properly governed by the vowel /a/), but also to the degemination of the glide, leading to wlijdat. This process suggests that there is a causal relationship between the presence of schwa and the gemination of the glide.

As to the forms in (4d-e) like $k^{w} t i j j a b$ 'little book' and $b b^{w} i j j a t$ 'small room', these show a labio-velarized initial consonant. This labio-velarization can be seen as a remnant of the vowel $u$ found in CA diminutives such as kulajb 'little dog'. In line with the proposal put forth in (7), this short vowel remains silent in MA unless it is adjacent to a labial or velar consonant, which allows it to surface as a round feature.

Biconsonantal forms further support the templatic effect since they geminate the initial consonant or use a glide in order to fill the whole template used in the diminutive. This is shown in (12) with the diminutive forms of $d^{\varsigma} a r$ 'house' and bit 'room'.

\footnotetext{
${ }^{13}$ This phenomenon is not limited to diminutives. It is also found in the plural formation (e.g. zili (sg) / zilijjat (pl) 'vest', biru (sg) / biruwwat (pl) 'office'). Further examples and discussion is found in Boudlal (2001: 280). It should be noted that in certain varieties of MA, the glide following the diminutive marker surfaces as non-geminated. The reader is referred to Elmdari (1999: 82) about the MA variety of Marrakech.
} 
(12) $a$.

DIM FM SG: $d$ wira

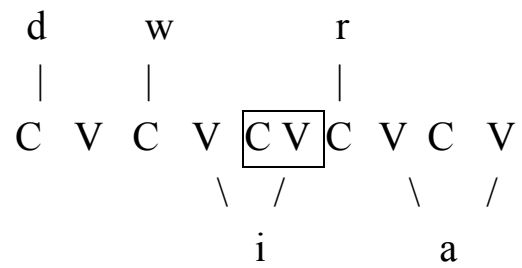

b.

DIM MS SG: $b b^{w} i j j a t$

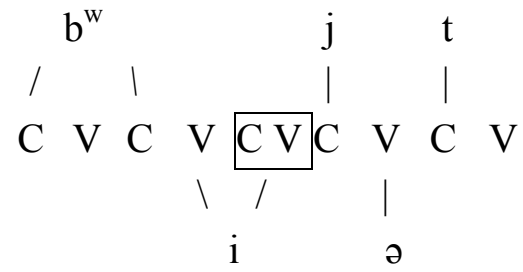

Quadriconsonantals (4f) behave similarly to the other forms, except that their template involves four basic $\mathrm{CV}$ units accommodating the root consonants, while the diminutive markers require two additional CVs. The second vowel can be viewed as a mere copy of the diminutive marker which appears between the last two consonants, exactly where a full vowel is found in the singular form. This behaviour is illustrated in (13) using the form sarwal 'pants' and its diminutive sriwil.

(13)

a. MS SG: sarwal

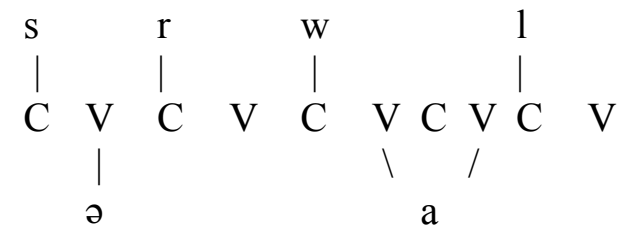

b. DIM MS SG: sriwil

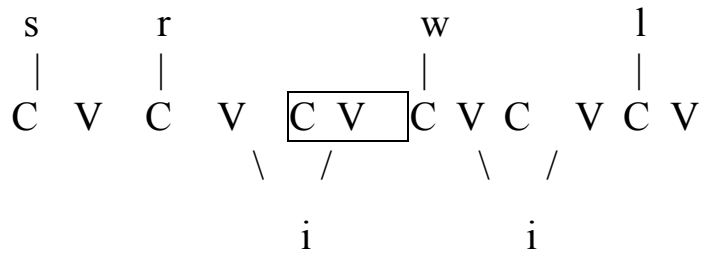

As we can see from these representations, the template of the diminutive (13b) is just the template of the masculine singular (13a) plus one CV unit which accommodates the diminutive marker /i/. The copy of this marker, viewed as a kind of harmony, appears exactly where the vowel /a/ is found in the basic form. This suggests a kind of prosodic transfer between the base and the diminutive. It is worth adding that triconsonantals containing a geminate behave in the same way as genuine quadriconsonantals as their diminutives involve double infixation of the vowel /i/ between the last three consonantal slots, two of which host a geminate. Thus for 
instance, masculine singular sallum 'ladder' and barrad 'tea pot' form their diminutive as slilim and bririd (see Boudlal 2001: 250 for further examples). This is readily accounted for by analysing the medial geminate as a single melodic unit associated to two $\mathrm{C}$ slots, making the base template quadriconsonantal.

In the next subsection, we turn to the central question of this section, namely why diminutives select for external plurals rather than internal ones.

\subsubsection{Templatic competition}

It is quite puzzling why the diminutive and non-diminutive forms of the same noun do not use the same plural formation. Why does the non-diminutive bəlya 'slipper' (4a) have an internal plural blayi, while its diminutive bliya 'little slipper' uses the suffix -at in the plural? Similarly, why does wald 'boy' lead to plural wlad whereas wlijjad 'little boy' forms it plural as wlijdat? The answer to these questions comes naturally if we assume that the diminutive and the internal plural markers compete for the same templatic position, namely the internal derivational CV. The diminutive forms bliya (14a) and wlijjad (14b) along with their non-diminutive plurals blayi (14c) and wlad (14d) illustrate this templatic competition.

(14) $a$.

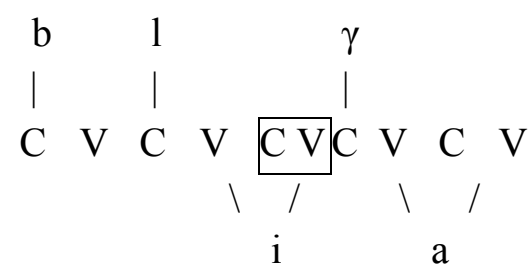

$c$.

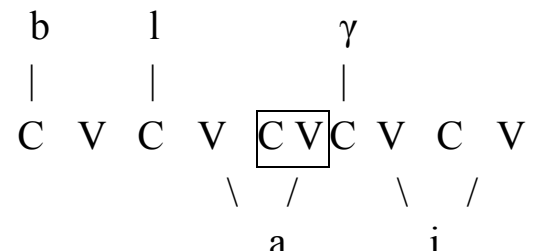

$b$.

DIM MS SG: wlijjad

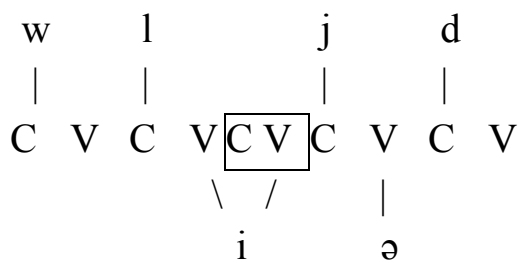

$d$.

MS PL: wlad

The vowel /a/ in blayi and wlad is a plural marker. It occurs exactly where the diminutive marker appears in the forms in $(14 a, b)$, namely between the last two radicals, attaching to two $\mathrm{V}$ 
slots, one of which belongs to the derivational (boxed) $\mathrm{CV}$. When the diminutive marker is realized, no vocalic position is left for the association of the plural marker. Therefore, the only option for diminutives to form their plural is to use the suffix -at, leading to bliyat and wlijdat. Competition therefore holds for a pre-specified position in the template, viz. the internal derivational $\mathrm{CV}$, rather than for the whole template. As stated earlier in section 2.3.3, this internal $\mathrm{CV}$ acts as a morphological head in the sense of Lowenstamm \& Guerssel (1990) and Lowenstamm (2003). Its identification by some phonological material derives one form. In the case at hand, it hosts either the diminutive or the internal plural marker, never both at the same time. A question one may ask is: why does the diminutive marker take precedence over the plural marker? Why is the diminutive formed before the internal plural?

In an attempt to implement our templatic analysis to a syntactic structure, we could argue that diminutive nouns, just as internal plurals, are projected within the domain of $\mathrm{nP}$, the head of which has plural and diminutive features. Given that the diminutive can be formed only under $n$ while the plural has two dedicated positions, one under $n$ and the other under num, the diminutive is generated first, before the plural is formed higher in the structure by means of -at suffixation. Another possibility is to assume that diminutives are derived lower in the structure than internal plurals, heading their own projection between the root and the head of $\mathrm{nP}$. This proposal is not new; the reader is referred to De Belder et al. (2015) for a similar proposal used to distinguish inflexional diminutives from lexical ones in Hebrew and Italian. However, MA has no such lexical and inflexional distinction in diminutives. An alternative analysis is found in Lampitelli (2010: 208) who argues that all diminutives in Italian are formed under DimP (i.e. Diminutive Phrase), lower in the structure than $\mathrm{nP}$. In line with this proposal, we claim that the derivational $\mathrm{CV}$ is the locus of phonological exponents of one or more syntactic terminals. It is generated under the projection immediately above the root, namely DimP. This derivational CV allows the diminutive marker /i/ to surface. When raised to the head of $\mathrm{nP}$, it has no more $\mathrm{V}$ position available for the realization of the internal plural marker, leaving -at suffixation as the only strategy for pluralization. ${ }^{14}$ The diminutive form bliyat illustrates the proposal in (15).

\footnotetext{
${ }^{14}$ As stated earlier in section 1, MA does show a few double plurals, such as mwasat 'knives' (plural of plural mwas) and qwasat 'arches' (plural of plural qwas). This supports our assumption that both $\mathrm{nP}$ and numP are the locus of plurality in MA.
} 
$(15)$

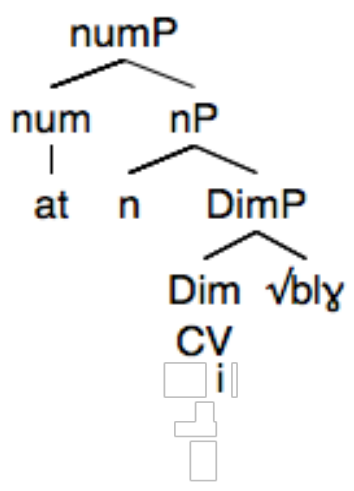

Following the hypothesis that the order of the affixes directly reflects the order of application of the morphosyntactic operations (cf. Baker's Mirror Principle, 1985) and that their position within the word mirrors their position in grammar (Scalise 1988: 235), the diminutive appears lower in the structure than the plural. Furthermore, the absence of the internal plural marker in diminutives is viewed as by-product of the templatic character of MA morphology. The internal derivational $\mathrm{CV}$ determines the distribution of grammatical markers, allowing the internal plural marker to surface only when the diminutive marker is absent.

Evidence for the linear order in which the diminutive precedes the plural is found in many other languages such as French char-ette ${ }_{D I M}-S_{\mathrm{PL}}$ 'carts', ois-illon-s 'chicks', Italian ros- $^{-i_{D I M}-e_{P L}}$

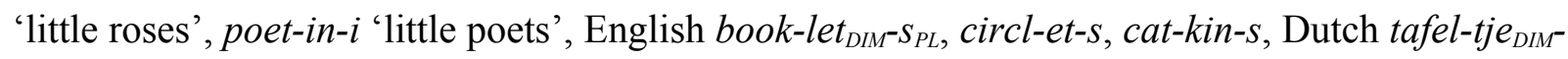
$s_{P L}$ 'small tables', huis-je-s 'small houses' (Booij 2002), and Bulgarian palt-ents ${ }_{D I M}-a_{P L}$ 'little coats' (Milenova 2009: 134). In contrast, certain forms in Yiddish exhibit an internal plural marker followed by the diminutive, but they all end with an external plural marker such as in xavejramlax $\left(\leftarrow\right.$ xavejr- $\left.\partial m_{P L}-l_{D I M}-\partial x_{P L}\right)$ 'the little friends' (Lowenstamm 2008). ${ }^{15}$

Further arguments for the lower position of diminutives are morphological and semantic. Morphologically speaking, we note that the diminutive forms in MA exhibit morphological irregularities. The allomorphic variation that their markers display does not only follow from templatic constraints, as we have shown above, but is also conditioned by gender features. That is, diminutive markers select bases of one gender value (masculine or feminine) and their formations preserve this value: The marker -ijj-, as in wlijjad $(\leftarrow$ wəld 'boy'), selects only

\footnotetext{
${ }^{15}$ Perlmutter (1988) analyzed the internal plural marker -am as part of suppletive forms, lexically specified as such. Alternatives to this approach are proposed in Lowenstamm (2008) and Newell (2008).
} 
masculine bases, while $i-a$, as in bnita ( $\leftarrow$ bənt 'girl'), selects feminine ones. No such property is found with internal plural markers whatever their surface form is. For example, the infix $-w a$ - is compatible with feminine (e.g. gamila $_{\mathrm{SG}} /$ gwaml $_{\mathrm{PL}}$ 'bowl') and masculine bases as well (e.g. $\hbar a n u t_{\mathrm{SG}} / \hbar$ want $_{\mathrm{PL}}$ 'room'). The reader is referred to Milenova (2009) for a similar argument in Bulgarian diminutives.

From a semantic perspective, MA diminutives refer not only to smallness but also to affection and tenderness, and can also have a pejorative connotation. Such polysemy is absent in plurals, except for collective readings associated with internal plurals.

The lower location of the diminutives in MA, closer to the root, accounts for these morphological and semantic properties. ${ }^{16}$ Similar arguments have been proposed in the analysis of diminutives in Modern Greek (Melissaropoulo \& Ralli 2008) and Bungarian as well (Milenova 2009).

We now turn back to the analysis advocated in section 1. External evidence for the hypothesis that broken and sound plurals reside in distinct syntactic positions is drawn from emphasis spread. We argue that emphasis spreads within the domain of nP.

\section{Emphasis spread}

\subsection{MA emphatic consonants}

The coronals $t^{\varsigma}, d^{\varsigma}, s^{\uparrow}, z^{\varsigma}$ and $r^{\varsigma}$ are the uncontroversial emphatics (pharyngealized) in MA as well as in many other Arabic varieties (see Benhallam 1980, Ghazali 1981, Younes 1993, Davis 1995, Zeroual 2000, Kenstowicz and Louriz 2009). There are important acoustic and articulatory differences between pharyngealized coronals and their plain counterparts, which result in clear auditory differences between items containing emphatic consonants and items containing plain ones. The acoustic differences are observed in terms of VOT durations for voiceless stops (the emphatic $/ t^{\mathrm{q}} /$, for instance, has a shorter VOT duration compared to its plain counterpart), and most importantly in terms of qualitative effects on adjacent vowels (see below). The articulatory differences are observed both at the supralaryngeal and laryngeal levels. At the supralaryngeal level, the emphatic coronals are produced with a backward movement of the tongue towards the

\footnotetext{
${ }^{16}$ For a thorough analysis of morpho-phonological and semantic irregularities within the domain of categorydefining projections, close to the root, the reader is referred to Marantz (2013). See also Arad (2003) about the interpretation of roots in Hebrew.
} 
posterior pharyngeal wall, while the anterior part of the tongue is substantially lowered. At the laryngeal level, voiceless emphatics have a smaller glottal opening, compared to their plain counterparts. The small glottal opening of $/ t^{\mathrm{f}} /$ is the most likely reason for the shorter VOT displayed by this segment.

At the surface level, emphasis is a property which can spread to any segment. For

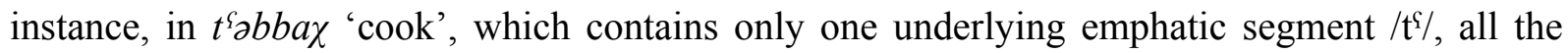
segments contained in the word are pharyngealized. The exact delimitation of the propagation of this feature is a source of much controversy. It is generally considered that the minimal and maximal domains of this propagation are the syllable and the word, respectively. According to Kenstowicz and Louriz (2009: 45): "Emphasis can spread in both directions and dialects differ as to which segments if any block (or minimize) the propagation. In MA the process is restricted to the stem and does not affect inflectional suffixes except that a $C V$ sequence must be realized uniformly as plain or emphatic".

Owing to frequent uncertainties in acceptability judgments, we have conducted an acoustic study to assess and establish the facts about emphasis spread in MA on experimental grounds. The acoustic data were recorded from three subjects producing thirty items with emphatic consonants in broken and internal plurals, as well as a set of minimal pairs contrasting emphatic to plain consonants.

\subsection{Plural formation and emphasis spread: acoustic data}

\subsubsection{Emphasis effect on vowels}

In all dialects of Arabic that have been acoustically investigated, pharyngealization is consistently manifested by a lowering of the second formant (F2) of the vowel following the emphatic consonant. This pattern has been observed in Egyptian Arabic (Wahba 1993), Lebanese Arabic (Obrecht 1968), Jordanian Arabic (Khattab et al. 2006), and Tunisian Arabic (Ghazeli 1981). The same pattern has been observed in MA based on our data, as figure 1 shows (see also Zeroual 2000 and Shoul 2007). 


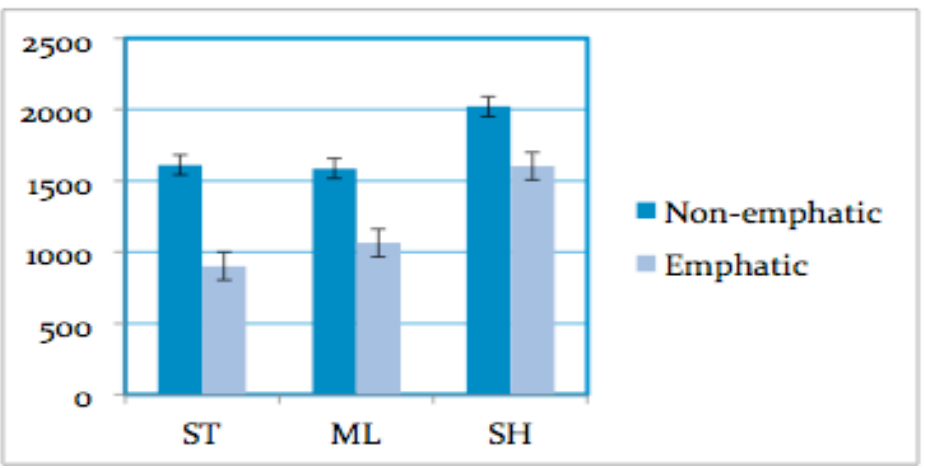

Figure 1. F2 values (in $\mathrm{Hz}$ ) showing the effect of emphasis on the following /a/ vowel for three subjects (ST, ML and SH).

The significant F2 drop after emphatic consonants can be attributed not only to their pharyngeal constriction, but also to the "simultaneous depression of the palatine dorsum" (Ali and Daniloff 1972: 100) compared to their non-emphatic cognates. The pharyngeal articulation during MA emphatics does not seem to be narrow enough to induce substantial raising of F1 (Zeroual et al. 2007).

Before addressing the question of how far emphatic consonants spread their feature in broken and sound plurals, we provide some background on phase theory and its implications for phonological derivation. This proves necessary to the understanding of our analysis, in particular the domain within which emphasis spreads.

\subsubsection{On phonological derivation by phase}

Recent studies have argued for a model of grammar in which pre-specified chunks of syntactic structure are sent to the phonological and semantic components, relying on Chomsky's (2001, 2008) proposal that syntactic derivations proceed by phase. This line of research has lead to a new movement in phonological theory, initiated by Marvin's (2002) fundamental work, which attempts to combine insights from early Lexical Phonology (Kiparsky 1982, 1985, Mohanan 1982, Rubach 1985) with Distributed Morphology (Halle and Marantz 1993, Marantz 1997 ) in order to account for non-automatic phonological processes that standard approaches fail to address in a satisfactory manner.

Generalizing from little vP (Chomsky 2001), Marantz (2001, 2007) argues that any category-forming projection, including $\mathrm{nP}, \mathrm{vP}$ and $\mathrm{aP}$, uniformly defines a phase that locally determines the phonological and semantic properties of words. From a phonological perspective, 
derivation by phase allows an explanation for certain phenomena confined to specific domains, suggesting that the whole material within a phase is spelled-out before any other operation is performed. In line with this proposal, Marvin (2002: 34) addressed among other things the opacity characterizing schwa-insertion in English meter [mi:tər], metric [metrik] and metering [mi:trrin]. According to the author, the reason that the vowel-initial suffix prevents schwa from appearing in metric as opposed metering lies in the fact that the adjectival suffix -ic is spelled-out in the same phase as /metr/, whereas the gerund marker -ing is added later in the syntactic structure, once meter is spelled-out along with its schwa. The Phase Impenetrability Condition (Chomsky 2001) is mobilized to explain why a previously-inserted schwa is not deleted. The same reasoning holds for the role of affixes in stress-assignment, Marvin argues.

Several studies have since generalized derivation-by-phase to phonological opacity in various languages, including Ojibwe (Pigott \& Newell 2014), Basque (Samuels 2010) and Berber (Lahrouchi 2013). The common denominator of these studies is that category-defining projections qualify as phases, which locally determine the domain of certain phonological processes.

One can still argue that derivation-by-phase is but a mere restatement of early phonological cycles (cf. Mascaró 1973, Kiparsky 1982, 1985, Mohanan 1982, Rubach 1985, among others), which proved useful to account for various types of phonological opacity including the aforementioned. However, while phases are morpho-syntactic domains, motivated outside the realm of phonology, phonological cycles may appear as ad hoc stipulations which lack any external evidence. That is to say, one can add as many cycles as needed to explain a given phonological phenomenon, whereas phases are morpho-syntactically constrained, none of which can be affected by phonology. Economy considerations further allow any spelled-out chunk to become impenetrable for following operations, thus leading to a grammar whose computation is much simpler in terms of memory load and processing.

In the next subsection, we return to emphasis spread in MA. We argue that phasal spellout better explains why the broken plurals are entirely pharyngealized while the sound plurals are affected only partially. 


\subsection{3. $n P$ as the domain of emphasis spread}

From our perspective, the projections of category-forming heads, including $\mathrm{nP}$, are the maximal domain of emphasis spread in MA. According to this view, broken plurals containing an emphatic consonant will be entirely pharyngealized, while sound plurals will be affected only partially. That is to say, $\mathrm{nP}$ demarcates a phase, wherein the broken plural is spelled out and is hence sensitive to emphasis spread. For instance, both $s^{\varsigma}$ abbat 'shoe' and $s^{\varsigma} b a b t$ 'shoes, IP' will

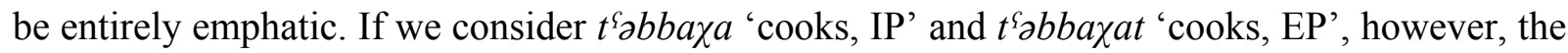
suffix -at along with the onset consonant $\chi$ are expected to remain unaffected by pharyngealization. We tested this through the analysis of the $2^{\text {nd }}$ formant of the vowel $/ a /$ in a series of triplets with internal and external plurals. Two such triplets are shown in (16), where the compared /a/'s are bolded and underlined.

\begin{tabular}{|c|c|}
\hline$/ t^{\complement} \partial \mathrm{s}^{\complement} \mathrm{wer} \underline{\mathbf{a}} /$ & "photo" \\
\hline$/ t^{\mathrm{f}} \mathrm{s}^{\mathrm{\complement}}$ awər/ & "photos, IP " \\
\hline$/ t^{\complement} \partial s^{\varsigma}$ werat & "photos, EP" \\
\hline$/ t^{\mathrm{S}} \partial \mathrm{bba \chi} /$ & "cook" \\
\hline$/ t^{\uparrow} \ni b b a \chi \mathbf{a} /$ & "cook, IP" \\
\hline 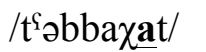 & "cook, EP" \\
\hline
\end{tabular}

Our results show a difference in F2 values of the two /a/ vowels. The vowel affected by emphasis displays, as expected, a lower F2 suggesting a more posterior realization characteristic of a dorsopharyngealized production. This pattern, illustrated in figure 2 , is observed for internal plural /a/ but not for the /a/ of the suffix $-a$ t. The differences between the two $a$ 's are rather easy to

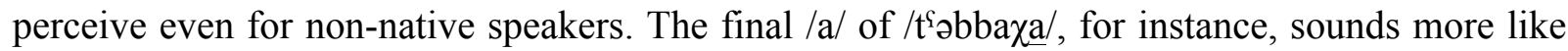
[a], whereas the /a/ of / $\mathrm{t}^{\text {`}}$ obbaxat/ is close to [æ]. 


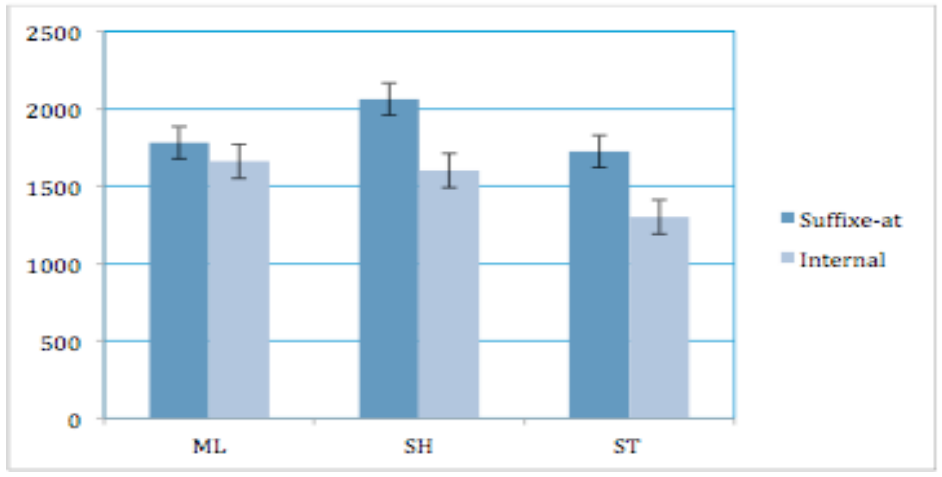

Figure 2. F2 values (in $\mathrm{Hz}$ ) showing the spread of emphasis on the internal /a/ vowel as opposed to the plain /a/ of the suffix -at.

Although both a's appear exactly in the same position with regard to base form, immediately following the final root consonant, their behaviour toward emphasis shows that they belong to different domains. That is to say, the broken plural $-a$ as in $t^{\zeta}$ abba $\underline{a}$ a is spelled out within the nP phase and is hence pharyngealized, while the sound plural suffix - at lies outside the phase, preventing its vowel from being pharyngealized. The same reasoning holds for the feminine marker $-a$ in $t^{\zeta} \partial s^{\uparrow}$ wer $\underline{a}$. Based on the assumption that gender is generated within the $\mathrm{nP}$, as a feature under $n$ (see Ritter 1993 and Lowenstamm 2008, among others), we naturally expect its phonological exponent to undergo pharyngealization just as in the broken plurals. Without such an interface approach, one can hardly understand why the same vowel in the same linear position behaves differently with respect to emphasis spread. Although diminutives have not been tested, we expect them to behave in the same manner with respect to emphasis spread-their singular forms entirely emphaticized since they are formed within the domain of $\mathrm{nP}$, while their plurals are affected only partially (e.g. / $\mathrm{s}^{\mathrm{S}} \mathrm{bijj} \mathrm{S} /$ / 'small finger' is realized as [s $\mathrm{s}^{\mathrm{s}}$ bejjəS] with its diminutive marker /i/ lowered to [e] since pharyngealized. However, in the corresponding plural [ $\mathrm{s}^{\mathrm{S}}$ bejjəSat] 'small fingers', the suffix -at resists pharyngealization because it lies outside the nP). ${ }^{17}$

\footnotetext{
${ }^{17}$ Further evidence for the phase-hood character of category-determining projections in MA comes from glide-vowel alternations. Like Berber (see Guerssel 1986, Lahrouchi 2013), MA has many instances of glide-vowel alternations which call for an analysis in terms of phasal derivation. Compare, for instance, $x u$ 'brother' to $x$ watat 'sisters'. The high vowel in the first form turns into a glide since it is immediately followed by the vowel $-a$. This alternation is automatic within a single domain, namely nP. However, in certain cases the same vowel remains unchanged as in $x u-j a$ 'my brother', while the possessive clitic turns its vowel $-i$ into [j] in order to avoid hiatus. The reason that the high vowel $u$ alternates with the glide $w$ in $x u / x w a t a t$ but not in $x u / x u$-ja can easily be explained if we assume that the alternation is automatic within the nP phase. In $x u-j a$, the segments following /u/, including the possessive clitic $-i(\mathrm{a})$, have no access to the phonological material already spelled-out .
} 


\section{Conclusion}

In this study, we have argued that internal (broken) and external (sound) plurals are located in distinct syntactic positions, namely $\mathrm{nP}$ for internal and NumP for external plurals. This analysis provides a principled way of capturing the morphological and semantic differences that internal and external plurals display. We have also provided a templatic account for the formation of diminutives. We have argued that the diminutive and internal plural markers compete for the same templatic position, forcing the diminutives to form their plural by means of suffixation. In an attempt to implement our templatic analysis to a syntactic structure, we have argued that diminutives are derived lower in the structure than internal plurals, heading their own projection between the root and the head of $\mathrm{nP}$. This allows us to explain why the diminutive marker takes precedence over the internal plural marker, forcing all diminutive forms to undergo external plural formation. Emphasis spread was used as evidence in support of the hypothesis that internal and external plurals reside in distinct syntactic positions. Based on acoustic data from three subjects, $\mathrm{nP}$ has been shown to be the domain of emphasis spread, evidenced from the F2 lowering characteristic of dorso-pharyngealization, observed in internal but not in external plurals. 


\section{References}

Acquaviva, Paolo. 2008. Lexical plurals: A morphosemantic approach. Oxford University Press.

Ali, Latif and Raymonf Daniloff. 1972. A contrastive cinefluorographic investigation of the articulation of emphatic-non emphatic cognate consonants. Studia Linguistica 26: 81-105.

Arad, Maya. 2003. Locality constraints on the interpretations of roots. Natural Language and Linguistic Theory 21:737-778.

Arad, Maya. 2005. Roots and Patterns: Hebrew Morpho-syntax. Dordrecht: Springer.

Baker, Mark. The mirror principle and morphosyntactic explanation. Linguistic Inquiry 16/3: 373-415.

Benhallam, Abderrafi. 1980. Syllable structure and rule types in Arabic. PhD dissertation, University of Florida.

Bennis, Said 1992. La formation du causatif en arabe marocain. Mémoire de D.E.S. Faculté des Lettres, Rabat.

Borer, Hagit. 2005. In name only, structuring sense, vol I. Oxford: Oxford University Press.

Booij, Geert. 2002. The Morphology of Dutch. Oxford: Oxford University Press.

Boudlal, Abdelaziz. 2001. Constraint Interaction in the Phonology and Morphology of Casablanca Moroccan Arabic. Doctorat d'Etat thesis, Mohammed V University, Rabat.

Chomsky, Noam. 2001. Derivation by Phase. In Ken Hale: A Life in Language, Michael Kenstowicz, (ed), 1-52. Cambridge: MIT Press.

Chomsky, Noam. 2008. On phases. In Foundational issues in linguistic theory: essays in honor of Jean-Roger Vergnaud, Robert Freidin, Carlos P. Otero, and Maria Luisa Zubizarreta (eds.), 133-166. Cambridge: MIT Press.

Davis, Stuart. 1995. Emphasis spread and Grounded Phonology. Linguistic Inquiry 26: 465-498.

De Belder, Marijke, Noam Faust \& Nicola Lampitelli (2015). On a low and a high diminutive: Evidence from Italian and Hebrew. In The Syntax of Roots and the Roots of Syntax, Artemis Alexiadou, Hagit Borer \& Florian Schäfer (eds), 149-163. Oxford: Oxford University Press.

Dell, François and Mohamed Elmedlaoui. 2002. Syllables in Tashlhiyt Berber and in Moroccan Arabic. Dordrecht: Kluwer Academic Publisher. 
Elmdari, Fouad. 1999. Aspects phonologiques et morphologiques du parler de Marrakech. PhD dissertation, Paris 8 University.

Embick, David and Alec Marantz. 2008. Architecture and Blocking. Linguistic Inquiry 39: 1-53.

Embick, David and Rolf Noyer. 2007. Distributed Morphology and the Syntax/Morphology interface. In The Oxford Handbook of Linguistic Interfaces, Gillian Ramchand \& Charles Reiss (eds), 289-324. Oxford: Oxford University Press.

Frajzyngier, Zygmunt. 2003. Tone and vowel deletion, insertion, and syllable structure. In Stress and tone: The African experience, Rose-Juliet Anyanwu (ed.). Frankfurter Afrikanistische Blätter 15: 83-98. Cologne: Koeppe.

Frajzyngier, Zygmunt. 2008. A Grammar of Gidar. Frankfurt: Peter Lang.

Ghazali, Salem. 1977. On the controversy of the Arabic "qāf". Texas Linguistic Forum 6: 40-50.

Ghazali, Salem. 1981. La diffusion de l'emphase. Analyses-Théorie 1: 122-135.

Guerssel, Mohamed. 1986. Glides in Berber and syllabicity. Linguistic Inquiry 17/1: 1-12.

Guerssel, Mohamed and Lowenstamm, Jean. 1990. The derivational morphology of the Classical Arabic verbal system. Ms. UQAM \& Université Paris 7.

Halle, Morris and Alec Marantz. 1993. Distributed Morphology and the pieces of inflection. In View from the building $20^{\text {th }}$, Kenneth Hale and Samuel J. Keyser (eds.), 111-176. MIT Press.

Hammond, Michael. 1988. Templatic transfer in Arabic broken plurals. Natural Language and Linguistic Theory 6: 247-270.

Heath, Jeffrey. 1987. Ablaut and ambiguity: Phonology of a Moroccan Arabic dialect. Albany: State University of New York Press.

Idrissi, Ali. 1997. Plural Formation in Arabic. In Perspectives on Arabic Linguistics: Papers from the Annual Symposium on Arabic Linguistics, volume X, Eid, Mushira and Robert R. Ratcliffe (eds.), 123-145. Amsterdam: John Benjamins.

Kaye, Jonathan and Jean Lowenstamm. 1984. De la syllabicité. In Forme Sonore du Langage, François Dell, Daniel Hirst \& Jean-Roger Vergnaud (eds.), 123-159. Paris: Hermann.

Kaye, Jonathan, Lowenstamm, Jean and Vergnaud, Jean-Roger. 1990. Constituent structure and government in phonology. Phonology 7-2: 193-231.

Kenstowicz, Michael and Nabila Louriz. 2009. Reverse engineering: Emphatic consonants and the adaptation of vowels in French loanwords into Moroccan Arabic. Brill's Annual of Afroasiatic Languages and Linguistics 1: 41-74. 
Khattab, Ghada, Feda Al-Tamimi and Barry Heselwood (2006). Acoustic and auditory differences in the /t/-/t/ opposition in male and female speakers of Jordanian Arabic. In Perspectives on Arabic Linguistics XVI: Papers from the sixteenth annual symposium on Arabic linguistics, Sami Boudelaa (ed.), 131-160. Cambridge: John Benjamins.

Kihm, Alain. 2003. Les pluriels internes de l'arabe : système et conséquences pour l'architecture de la grammaire. Recherches Linguistiques de Vincennes 32: 109-156.

Kihm, Alain. 2006. Nonsegmental concatenation: a study of Classical Arabic broken plurals and verbal nouns. Morphology 16: 69-105.

Kiparsky, Paul. 1982. From cyclic to lexical phonology. In The Structure of Phonological Representations, vol. I, Harry van der Hulst \& Norval Smith, (eds), 131-75. Dordrecht, The Netherlands: Foris Publications.

Kiparsky, Paul. 1985. Some consequences of lexical phonology. Phonology Yearbook 2: 83-138.

Kiparsky, Paul (2003). Syllables and moras in Arabic. In The syllable in Optimality Theory, Caroline Féry \& Ruben van de Vijver (eds.), 147-182. Cambridge: Cambridge University Press.

Kramer, Ruth. 2012. A split analysis of plurality: Evidence from Amharic. In The proceedings of WCCFL 30, Nathan Arnett and Ryan Bennett (eds.), 226-236. Somerville, MA: Cascadilla.

Lahrouchi, Mohamed. 2013. A propos de I et de U en berbère: de la phonologie, de la morphologie et des phases. In Phonologie, morphologie, syntaxe, Ali Tifrit (ed.), 21-30. Presses Universitaires de Rennes.

Lahrouchi, Mohamed \& Nicola Lampitelli. 2014. On plurals, noun phrase and number in Moroccan Arabic and Djibouti Somali. In The Structure of Form, The Form of Structure: Essays in honor of Jean Lowenstamm, Sabrina Bendjaballah, Noam Faust, Mohamed Lahrouchi \& Nicola Lampitelli (eds.), 303-314. Amsterdam/Philadelphia: John Benjamins Publishing Company.

Lampitelli, Nicola. 2010. Nounness, gender, class and syntactic structures in Italian nouns. In Romance Languages and Linguistic Theory 2008. Selected papers from 'Going Romance' Groningen 2008, Reineke Bok-Bennema, Brigitte Kampers-Manhe and Bart Hollebrandse (eds.), 195-214. Amsterdam: John Benjamins.

Lampitelli, Nicola. 2013. The decomposition of Somali nouns. Brill's Annual of Afroasiatic Languages and Linguistics 5: 117-158. 
Lecarme, Jacqueline. 2002. Gender polarity: Theoretical aspects of Somali Nominal Morphology. In Many Morphologies, Paul Boucher (ed), 109-141. Somerville: Cascadilla Press.

Lowenstamm, Jean. 1991. Vocalic Length and Centralization in Two Branches of Semitic (Ethiopic and Arabic). Semitic Studies in honor of Wolf Leslau on the occasion of his eightyfifth birthday, Alan S. Kaye (ed.), 949-965. Wiesbaden: Otto Harrassowitz.

Lowenstamm, Jean. 1996. CV as the only syllable type. Current Trends in Phonology: Models and Methods, Volume 2, ed. by Jacques Durand and Bernard Laks, 419-441. Salford: European Studies Research Institute, University of Salford.

Lowenstamm, Jean. 2003. A propos des gabarits. Recherches Linguistiques de Vincennes 32: 730.

Lowenstamm, Jean. 2008. On $n, \mathrm{nP}, \sqrt{ }$ and types of nouns. In The Sounds of Silence: Empty Elements in Syntax and Phonology, Jutta Hartmann, Vera Hegedüs and Henk van Riemsdijk (eds), 105-144. Amsterdam: Elsevier.

Marantz, Alec. 2001. Words. Ms, MIT.

Marantz, Alec. 2007. Phases and words. In Phases in the Theory of Grammar, 191-222. Seoul: Dong In.

Marantz, Alec. 2013. Locality domains for contextual allomorphy across the interfaces. In Distributed Morphology Today, Ora Matushansky and Alec Marantz (Eds.), 95-115. Cambridge, MA: MIT Press.

Marvin, Tatiana. 2002. Topics in the stress and syntax of words. PhD dissertation, MIT.

Mascaró, Joan. 1976. Catalan phonology and the phonological cycle. Cambridge, MA: MIT dissertation.

McCarthy, John. 1979. Formal problems in Semitic phonology and morphology. MIT, PhD dissertation. Distributed by Indiana University Linguistics Club, New York: Garland Press.

McCarthy, John. 1981. A prosodic theory of nonconcatenative morphology. Linguistic Inquiry 12: $373-418$.

McCarthy, John and Alan Prince. 1990. Foot and word in prosodic morphology: The Arabic broken plurals. Natural Language and Linguistic Theory 8: 209-283.

Melissaropoulou, Dimitra and Angela Ralli 2008. Headedness in diminutive formation: Evidence from Modern Greek and its dialectal variation. Acta Linguistica Hungarica 55: 183-204 
Milenova, Milena. 2009. Diminutive suffixes in Bulgarian. Patras Working Papers in Linguistics Volume 1: 127-147.

Mohanan, Karuvannur Puthanveettil. 1982. Lexical phonology. Cambridge, MA: MIT dissertation.

Newell, Heather. 2008. Aspects of the morphology and phonology of phases. $\mathrm{PhD}$ dissertation, McGill University, Montréal.

Newman, Paul. 2000. The Hausa language: An encyclopedic reference grammar. Yale: Yale University Press.

Obrecht, Dean. 1968. Effects of the second formant on the perception of velarization consonants in Arabic. The Hague: Mouton

Perlmutter, David. 1988. The Split Morphology Hypothesis: Evidence from Yiddish. In Theoretical Morphology, Michael Hammond and Michael Noonan (eds), 79-99. San Diego: Academic Press, Inc.

Piggott, Glyne and Heather Newell. 2014. Interactions at the syntax-phonology interface: Evidence from Ojibwe. Lingua 150: 332-362.

Puglielli, Annarita and Ciise Maxamed Siyaad. 1984. La flessione del nome. In Aspetti Morfologici, lessicali e della focalizzazione, (Studi Somali 5), Annarita Puglielli (ed.), 53112. Rome: MAE, Dipartimento per la Cooperazione allo Sviluppo.

Ratcliffe, Robert. 1997. Prosodic templates in a word-based morphological analysis of Arabic. In Perspectives on Arabic linguistics X, Mushira Eid and Robert Ratcliffe (eds.), 147-171. Amsterdam: John Benjamins.

Ritter, Elizabeth. 1993. Where's Gender?. Linguistic Inquiry 24/4: 795-803.

Rubach, Jerzey. 1985. Lexical phonology: lexical and postlexical derivations. Phonology Yearbook 2: 157-72.

Samuels, Bridget. 2010. Phonological derivation by phase: Evidence from Basque. University of Pennsylvania Working Papers in Linguistics 16: 166-175.

Scalise, Sergio. 1988. The notion of head in Morphology. Yearbook of Morphology 1: 229-245.

Shaw, Jason, Gafos, Adamantios I., Hoole Philip \& Zeroual, Chakir. 2009. Syllabification in Moroccan Arabic: evidence from patterns of temporal stability in articulation. Phonology 26: $187-215$.

Shoul, Karim. 2007. Etude physiologique, articulatoire, acoustique, perceptive de l'emphase en 
arabe marocain oriental. Thèse de Doctorat, Université Paris 3.

Wahba, Kassem. 1993. A sociolinguistic treatment of the feature of emphasis in Egypt. $\mathrm{PhD}$ dissertation, University of Texas at Austin.

Wright, William. 2004. Arabic grammar. New York: Dover Publications.

Younes, Munther. 1993. Emphasis spread in two Arabic dialects. In Perspectives on Arabic Linguistics, VI. M. Eid and C. Holes (eds.), 119-145. Amsterdam: John Benjamins.

Zeroual, Chakir. 2000. Propos controversés sur la phonétique et la phonologie de l'arabe marocain. Thèse de doctorat, Université Paris 8.

Zeroual, Chakir, Hoole, Phil, Fuchs, Susanne, Esling, John H. 2007. EMA study of the coronal emphatic and non-emphatic plosive consonants of Moroccan Arabic. Proceedings of the XVIth ICPHS, 397-340, Saarbrücken. 